\title{
Application of Control Measures for Infections Caused by Multi- resistant Gram-negative Bacteria in Intensive Care Unit Patients
}

\author{
Sinaida Teixeira Martins, Marina Moreira, Guilherme Henrique Campos Furtado+, \\ Cristiane Grande Jimenez Marino, Flávia Ribeiro Machado, Sergio Barsanti Wey, \\ Eduardo Alexandrino Servolo Medeiros
}

\author{
Comissão de Epidemiologia Hospitalar, Disciplina de Doenças Infecciosas e Parasitárias, Departamento de Medicina, \\ Universidade Federal de São Paulo, Rua Napoleão de Barros 715, $7^{\circ}$ andar, 04024-002 São Paulo, SP, Brasil
}

\begin{abstract}
Multi-resistant gram-negative rods are important pathogens in intensive care units (ICU), cause high rates of mortality, and need infection control measures to avoid spread to another patients. This study was undertaken prospectively with all of the patients hospitalized at ICU, Anesthesiology of the Hospital São Paulo, using the ICU component of the National Nosocomial Infection Surveillance System (NNIS) methodology, between March 1, 1997 and June 30, 1998. Hospital infections occurring during the first three months after the establishment of prevention and control measures (3/1/97 to 5/31/97) were compared to those of the last three months (3/1/98 to 5/31/98). In this period, 933 NNIS patients were studied, with 139 during the first period and 211 in the second period. The overall rates of infection by multi-resistant microorganisms in the first and second periods were, respectively, urinary tract infection: 3.28/1000 patients/day; 2.5/1000 patients/day; pneumonia: 2.10/1000 patients/day; 5.0/ 1000 patients/day; bloodstream infection: 1.09/1000 patients/day; 2.5/1000 patients/day. A comparison between overall infection rates of both periods (Wilcoxon test) showed no statistical significance $(\mathrm{p}=0.067)$. The use of intervention measures effectively decreased the hospital bloodstream infection rate ( $\mathrm{p}<0.001)$, which shows that control measures in ICU can contribute to preventing hospital infections.
\end{abstract}

Key words: intensive care unit infections - multi-resistant gram-negative bacteria - Pseudomonas aeruginosa - Acinetobacter baumannii

Throughout the 60s, intensive care units (ICUs) were created in order to provide care for patients that were physiologically unstable and seriously ill. These units are equipped with high-technology equipment and potent medicines such as antimicrobial drugs, which in addition to aiding to stabilize the clinical state of the patient and cure the illness, expose the individuals under their care to the risk of developing hospital infections (Pedrosa \& Couto 1997).

In addition to morbidity, mortality is also a consequence of infections acquired in hospital environments. According to Febré et al. (1999), the mortality rate in ICUs reaches nearly $40 \%$, and hospital infections contribute decisively to this rate. Constantin et al. (1987) showed that the mortality rate was $33.7 \%$ in hospitalized patients that developed hospital infections, against $14.5 \%$ in those who did not develop infections.

In the ICU, Anesthesiology of the Hospital São Paulo (HSP), Federal University of São Paulo, out of all infections developed in 1998, 22.1\% were of the bloodstream, $22.6 \%$ of the lower respiratory tract, $24.2 \%$ of the urinary tract, and $31.1 \%$ of other sites. In order to evaluate the impact of the application of control measures for infec-

${ }^{+}$Corresponding author. Fax: $+55-11-5571.8935$. E-mail: ghfurtado@uol.com.br

Received 5 September 2003

Accepted 12 April 2004 tions caused by multi-resistant gram-negative bacteria in patients in intensive care units, we undertook the present study.

\section{MATERIALS AND METHODS}

HSP is an educational institution that belongs to the Federal University of São Paulo (Unifesp), located in São Paulo. It is a large-scale, public, general hospital. It has 644 beds, distributed in 25 wards with several specialties. In 1997 and 1998 there were, respectively, 22,387 and 25,248 hospitalizations in HSP units, the average occupation was $72.83 \%$ and $75.73 \%$ respectively, and the average stay for patients in the hospital was 7.65 and 7.06 days respectively.

HSP has two general intensive care units for adults (Anesthesiology and Internal Medicine) and one pediatric, and seven intensive care units specialized in the following areas: Pneumology, Cardiology, Thoracic Surgery, Nephrology, Gastric Medicine, Neurosurgery, and Infectious and Parasitic Diseases. The ICU-Anesthesiology has a capacity of 16 beds, with 10 distributed in a large ward and three smaller ones with two beds each, destined for isolation. It has a hallway that links the four areas, and a room reserved for drug preparation. It serves mostly surgical patients from Emergency Room and from the specialized clinics.

Since 1993, hospital infections are monitored in the ICU with the NNISS (National Hospital Infection Surveillance System) methodology using the ICU component, as recommended by the Centers for Disease Control and Prevention (CDC) (Emori et al. 1991). The data for this 
study was collected between 3/1/97 and 6/30/98. The ICU component of the NNISS methodology was used for epidemiological monitoring of hospital infections. The intervention was characterized by educational and control measures after early identification of infected patients at ICU through laboratory monitoring of clinically requested cultures. The following measures were implemented: (a) identify the isolated patient's bed with a color-coded plate according to the isolated microorganism, as well as notification with a Infection Control document in the patient's records; (b) wash hands with antiseptic solution (PVP-I or chlorexidine) before and after contact with the patient; (c) application of contact isolation measures: (1) contact precautions through the obligatory use of gloves and gowns during direct contact with the patient; (2) separation of stethoscopes, thermometers, and sphyngmomanometers for individual use; (3) daily surface cleaning and disinfection with alcohol at 70\%; (4) separation of articles and equipment for exclusive use of the patient.

The following were considered multi-resistant microorganisms: Acinetobacter baumannii and Pseudomonas aeruginosa, resistant to aminoglycosides, quinolones, third-generation cephalosporins, and carbapenems. These two pathogens have been chosen because they are the most resistant at our facility. According to data colected between 1986 and 1998 by NNIS, P. aeruginosa was the second most common cause of nosocomial pneumonia (14\% of isolates), the third most common cause of urinary tract infections (7\%), the fourth more common cause of surgical site infection (8\%) and the seventh most frequently isolated pathogen from the bloodstream (2\%) and the fifth most common isolate (9\%) overall from all sites (NNIS 1998). The resistance to Imipenem in Latin America was 16\% in 1999 (Gales et al. 2001b).

Acinetobacter spp. are ubiquitous organisms widely distributed in nature, and are usually commensal, but in the past few decades they have emerged as important opportunistic pathogens, especially in the nosocomial setting (Bergogne-Bérézin \& Towner 1996). The SENTRY Antimicrobial Surveillance Program shows in Latin America, 10.3\% of resistance to Imipenem between 1997 and 1999 (Gales et al. 2001a).

Infections were notified through an active search according to the diagnostic concepts and criteria defined by CDC (Garner et al. 1988) .

For univariate analysis we used the chisquare test, and for comparison of data between the two periods (preand post-intervention) we used the Wilcoxon test. The work was approved by the Internal Review Board.

\section{RESULTS}

During this period, 973 NNISS patients were hospitalized. The average for hospital infections was 54.4 per 1000 patients/day. Urinary tract infections were the most frequent (14.4/1000 patients/day, with 3.6/1000 patients/day caused by multi-resistant gram-negative microorganisms), associated to an $87 \%$ urinary catheter usage rate. The second most frequent were pneumonias (13.1/1000 patients/day, with 3.1/1000 patients/day caused by multiresistant gram-negative microorganisms), with a $63.7 \%$ ventilator utilization rate. Finally, bloodstream infections
(12.8/1000 patients/day, with $1.3 / 1000$ patients/day caused by multi-resistant gram-negative microorganisms), with a $74.4 \%$ central venous catheter usage rate. Other infections, including surgical wound and skin infections (12.4/ 1000 patients/day, with 3.6/1000 patients/day caused by multi-resistant gram-negative microorganisms).

The three first months after the establishment of prevention and control measures, from 3/1/97 to 5/31/97, corresponding to the first period, were compared to the last three months, from $3 / 1 / 98$ to $5 / 31 / 98$, which correspond to the second period. The percentage of usage of invasive procedures in the first period was the following: ventilators, $64.3 \%$; central venous catheters, $86.9 \%$; urinary catheters, $92 \%$. In the second period, ventilators were used for $57.9 \%$ of the patients; central venous catheters for $73 \%$; and urinary catheters for $86.5 \%$ of the patients (Table I).

\section{TABLE I}

Percentage of invasive procedures used for patients in the adult intensive care unit of the Hospital São Paulo during the pre- and post-intervention periods

\begin{tabular}{lcc}
\hline Procedure & $\begin{array}{c}\text { 1st period } \\
(3 / 1 / 97 \text { to 5/31/97) }\end{array}$ & $\begin{array}{c}\text { 2nd period } \\
(3 / 1 / 98 \text { to 5/31/98) }\end{array}$ \\
\hline Ventilator & $64.3 \%$ & $57.9 \%$ \\
Central venous catheter & $86.9 \%$ & $73 \%$ \\
Urinary catheter & $92 \%$ & $86.5 \%$ \\
\hline
\end{tabular}

In the first period, the average rate of urinary infection was 14.1/1000 patients/day; with 3.2/1000 patients/day caused by multi-resistant gram-negative microorganisms; the average rate of pneumonia was 26.2/1000 patients/ day, with 2.1/1000 patients/day caused by multi-resistant gram-negative microorganisms. The average rate of bloodstream infection was 23/1000 patients/day, with 1.0/1000 patients/day due to multi-resistant gram-negative microorganisms. Other areas (surgical wound and skin infections) presented an average rate of 19.7/1000 patients/ day, with 7.6/1000 patients/day due to multi-resistant gramnegative microorganisms.

In the second period (after establishment of the measures), the average rate of urinary tract infection was 8.3/ 1000 patients/day, with 2.5/1000 patients/day caused by multi-resistant gram-negative microorganisms; the average rate of pneumonia was 15/1000 patients/day, with 5/ 1000 patients/day due to multi-resistant gram-negative microorganisms; the average rate of bloodstream infection was 4.1/1000 patients/day, with 2.5/1000 patients/day caused by multi-resistant gram-negative microorganisms. In other areas, the average rates were $18.3 / 1000$ patients/ day, with 4.1/1000 patients/day caused by multi-resistant gram-negative microorganisms. In second period there was increase in multi-resistant pathogens from $22.7 \%$ to $30 \%$ in UTI, from $8.3 \%$ to $33.3 \%$ in pneumonia and from $4.7 \%$ to $60 \%$ in BSI. This data can be better understood by viewing Table II. When comparing the overall rates of infection between the first and second periods regardless of area of infection (Wilcoxon test), no statistically significant decrease was observed $(p=0.067)$. 
TABLE II

Comparison of hospital infection rates in the various areas and rates of infection caused by multi-resistant gram-negative bacteria in the pre- and post-intervention periods in the adult intensive care unit of Hospital São Paulo

\begin{tabular}{|c|c|c|c|c|}
\hline \multirow[b]{2}{*}{ Type of infection } & \multicolumn{2}{|c|}{ 1st period $(3 / 1 / 97$ to $5 / 31 / 97)$} & \multicolumn{2}{|c|}{ 2nd period $(3 / 1 / 98$ to $5 / 31 / 98)$} \\
\hline & Infection rates ${ }^{a}$ & $\begin{array}{l}\text { Multi-resistant } \\
\text { microorganisms }\end{array}$ & Infection rates ${ }^{a}$ & $\begin{array}{l}\text { Multi-resistant } \\
\text { microorganisms }\end{array}$ \\
\hline UTI & 14.14 & 3.28 & 8.33 & $2.5 \mathrm{p}=0.10^{b}$ \\
\hline Pneumonia & 26.28 & 2.19 & 15.0 & $5.0 \mathrm{p}=0.05^{b}$ \\
\hline BSI & 23.0 & 1.09 & 4.16 & $2.5 \mathrm{p}<0.001^{b}$ \\
\hline Others & 19.71 & 7.68 & 18.33 & $4 \mathrm{p}=0.86^{b}$ \\
\hline
\end{tabular}

$a$ : rates calculated per 1000 patients/day; $b$ : $\mathrm{p}$ values refer to a comparison of the infection rates per area between the first and second period; UTI: urinary tract infection; BSI: bloodstream infection; Others: include surgical and skin infection.

\section{DISCUSSION}

ICUs are responsible for the highest rates of infection acquired in the hospital environment (Brown et al. 1995). The most commonly acquired infections in ICUs include bloodstream infection, pneumonia, and urinary tract infection (Fridkin et al. 1997).

During the period studied, the main infection observed in our ICU was urinary tract infection (14.46/1000 patients/ day), followed by pneumonia and bloodstream infection. When both periods were analyzed, we noted that the utilization rates of invasive procedures were very similar (Table I). This fact probably shows that in both periods we found patients with similar conditions.

We also noted that there was a change in the order of appearance of the main hospital infections, with pneumonia being the most frequent in both, followed by bloodstream infection in the first period and urinary tract infection in the second period (Table II). Kerver et al., in 1987, observed that gram-negative colonization of the respiratory, digestive, and oropharyngeal tract in patients hospitalized in ICUs increased during their stay in this unit, as well as their chance of developing bacteremia and infection by those microorganisms.

Colonization by $P$. aeruginosa at the time of admission in the ICU was associated by Olson et al., in 1984, to the length of stay in other in-patient hospital units, age, gastrointestinal illness, and previous usage of antibiotics. In this same study there were faults in the efficiency of control measures, which are attributed by the author to patients colonized during admission to the intensive care unit.

According to Weinstein (1991) infection control measures in ICUs are deficient due to their limited impact on the microbes endogenous to the own patient, which are an important source of infection in ICUs. In a study done by D'Agata et al. (1999), it was noted that, out of 333 ICU patients in a tertiary hospital, $60(18 \%)$ were colonized by gram-negative rods resistant to ceftazidime, and many of these patients colonized or infected by such microorganisms were positive in screening cultures at the time of admission into the ICU. In the studies cited the main objective is to try to identify patients that are already colonized at the time of admission into the ICU, whether through endogenous flora or through acquisition during previ- ous hospitalization in other sectors.

Control measures for multi-resistant microorganisms include standard precautions and isolation measures, although Preston et al., in 1981, demonstrated that isolation in private rooms did not reduce hospital infections when compared to open units. The study also showed that contact between the patient and health professionals was not always preceded by washing hands, a fact that contributed to the acquisition of hospital infections.

There was a decrease in the bloodstream infection rate $(p<0.001)$ when we compare the two periods which shows that control measures in ICUs can prevent hospital infections reducing morbidity, mortality and the resulting costs. This study allowed us to conclude that the incidence of hospital infections in the intensive care unit was 54.4/1000 patients/day. Urinary tract infections occurred most frequently in the unit (14.4/1000 patients/day), and the same applied to multi-resistant gram-negative microorganisms (3.6/1000 patients/day).

The usage of control measures did not alter the infection rates by multi-resistant gram-negative microorganisms, probably due to the fact that the study did not evaluate risk factors such as: the previous usage of antimicrobial drugs, immunodepression and screening cultures at the time of admission into the ICU related to the length of hospital stay .

On the other hand, in the second period we observed a decrease in the overall infection rates, especially in bloodstream infections $(p<0.001)$. When the overall infection rates of the first and second period were compared (Wilcoxon test), no statistically significant differences were found $(p=0.067)$. Despite the efforts undertaken with the establishment of educational measures and isolation of the patients colonized/infected, this study shows significant increase in percentage of multi-resistant pathogens in second period comparing to first period. In UTI there was increase in multi-resistant from $22.7 \%$ to $30 \%$, in pneumonia there was increase from $8.3 \%$ to $33.3 \%$ and in BSI from $4.7 \%$ to $60 \%$. This study shows the complexity in manegement of multi-resistant microorganisms in ICUs that include several measures beyond that discussed in this study as rational usage of antimicrobials. In conclusion, new interventions must be evaluated for the control of multi-resistant microorganisms in our environment. 


\section{ACKNOWLEDGEMENTS}

To Dr Marise Freitas and Nurse Gisele de Jesus Batistini for their collaboration during the development of this study.

\section{REFERENCES}

Bergogne-Bérézin E, Towner KJ 1996. Acinetobacter species as nosocomial pathogens: microbiological, clinical, and epidemiological features. Clin Microbiol Rev 9: 148-165.

Brown RB, Colodny SM, Drapkin MS 1995. One-day prevalence study of nosocomial infections, antibiotic usage, and selected infection control practices in adult medical/surgical intensive care units in the United States [abstract]. The Fifth annual meeting of the Society for Healthcare Epidemiology, San Diego, CA, April 2-4, Infect Control Hosp Epidemiol 16 (Suppl. 2): 10.

Constantin J, Donisi PM, Turrin MG, Diana L 1987. Hospital acquired infections surveillance and control in intensive care services, results of an incidence study. Eur J Epidemiol 3: 347-35.

D’Agata EMC, Venkataraman L, Girolami P, Burke P, Eliopoulos GM, Karchmer AW, Samore MH 1999. Colonization with broad-spectrum cephalosporin-resistant gram-negative bacili in intensive care units during a nonoutbreak period: prevalence, risk factors, and rate of infection. Crit Care Med 27: 1090-1095.

Emori TG, Culver DH, Horan TC, Jarvis WR, White JW, Olson DR, Banerjee S, Edwards JR, Martone WJ, Gaynes RP, Hughes JM 1991. National Nosocomial Infections Surveillance System (NNISS): description of surveillance methods. Am J Inf Control 19: 19-35.

Febre N, Silva V, Medeiros EAS, Wey SB, Colombo AL, Fishman O 1999. Microbiological characteristics of yeasts isolated from urinary tract of intensive care unit patients undergoing urinary catheterization. J Clin Microbiol 37: 1584-1586.

Fridkin SK, Welbel SF, Weinstein RA 1997. Magnitude and prevention of nosocomial infections in the intensive care unit. Infect Dis Clin North Am 11: 479-497.
Gales AC, Jones RN, Forward KR, Liñares J, Sader HS, Verhoef J 2001a. Emerging importance of multidrug-resistant Acinetobacter species and Stenotrophomonas maltophilia as pathogens in seriously ill patients: geographic patterns, epidemiological features, and trends in the SENTRY Antimicrobial Surveillance Program (1997-1999). Clin Infect Dis 32 (Suppl. 2): 104-113.

Gales AC, Jones RN, Turnidge J, Rennie R, Ramphal R 2001b. Characterization of Pseudomonas aeruginosa isolates: ocorrence rates, antimicrobial susceptibility patterns, and molecular typing in the global SENTRY antimicrobial surveillance program, 1997-1999. Clin Infect Dis 32 (Suppl. 2): S146-155.

Garner JS, Jarvis WR, Emori TG, Hughes JM 1998 CDC definitions for nosocomial infections. Am J Infect Control 16: 128-140.

Kerver AJH, Rommes JH, Mevissen-Verhage, Hulstaert PF, Vos A, Verhoef J, Wittebol P 1987. Colonization and infection in surgical intensive care patients. Intensive Care Med 13: 347-351.

NNISS-National Nosocomial Infections Surveillance 1998. System report: data summary from October 1986-April 1998. Am J Infect Control 26: 522-533.

Olson B, Weinstein R A, Nathan C, Chamberlin W, Kabins SA 1984. Epidemiology of endemic Pseudomonas aeru-ginosa: Why infection control efforts have failed. J Infect Dis 150 : 808-816.

Pedrosa TMG, Couto RC 1997. Adult and pediatric intensive care units. In RC Couto, TMG Pedrosa, JM Nogueira (eds), Infecção Hospitalar Epidemiologia e Controle, Medsi, Rio de Janeiro, p. 405-418.

Preston GA, Larson RN, Stamm WE 1981. The effect of private isolation rooms on patient care practices, colonization and infection in an intensive care unit. Am J Med 70: 641645.

Weinstein RA 1991. Epidemiology and control of nosocomial infections in adult intensive care units. Am J Med 91 (Suppl. 3B): 179S-184S. 